\title{
Behavioral and health problems of poultry related to rearing systems
}

\author{
Renata RELIĆ ${ }^{1, a, ®}$, Evangelia SOSSIDOU ${ }^{2, b}$, Anna DEDOUSI ${ }^{2, c}$, Lidija PERIĆ $^{3, d}$, \\ Ivana BOŽIČKOVIĆ1,e, Mirjana ĐUKIĆ-STOJČIĆ ${ }^{3, f}$
}

\begin{abstract}
${ }^{1}$ University of Belgrade, Faculty of Agriculture, Department of Animal Science, Belgrade, Serbia; ${ }^{2}$ Veterinary Research Institute, Hellenic Agricultural Organization-Demeter, Thessaloniki, Greece; ${ }^{3}$ University of Novi Sad, Faculty of Agriculture, Department of Animal Science, Novi Sad, Serbia.

${ }^{\mathrm{a} O R C I D: ~ 0000-0001-5320-7863 ; ~ b ~ O R C I D: ~ 0000-0002-5716-0908 ; ~ ' ~ O R C I D: ~ 0000-0002-5399-9773 ; ~}$

${ }^{\mathrm{d} O R C I D:}$ 0000-0002-2151-4516; ${ }^{\mathrm{e} O R C I D: ~ 0000-0001-6151-4273 ; ~}{ }^{\mathrm{f}}$ ORCID: 0000-0002-0784-3671
\end{abstract}

Corresponding author: rrelic@ agrif.bg.ac.rs

Received date: 27.07.2019- Accepted date: 01.09.2019

\begin{abstract}
This review paper aims to give an overview of the literature data on common behavioral and health problems in broiler chickens and laying hens and to explain their interrelation and relation to the rearing system. In the initial part, the mechanism of arising of the most common forms of abnormal behavior and the way they affect the poultry are briefly described. Furthermore, the possibility of poultry to fulfill behavioral needs in different rearing systems and some of the consequences to the birds in the case of their inability to meet their needs are displayed. The influence of the main microclimate and space factors is also discussed, as well as the occurrence of some infectious, parasitic and production diseases in poultry rearing systems. The welfare problems of poultry are complexes and most often caused by the system design and its improper use. Continuous work on improving rearing systems is as important as better informing the producers and the public on poultry welfare problems.
\end{abstract}

Keywords: Behavior, health, broilers, hens, rearing.

\section{Introduction}

Poultry production for decades has had the status of the fast-growing agricultural sector, and it is expected to continue to grow along with demand for poultry meat and eggs. The progress has been made by changes in technology which increased the number of birds per farmer and labor productivity, and also by selective breeding directed to improving the size, fecundity and growth rate of birds $(13,50)$. However, intensification of the production has also resulted in many welfare problems manifested as damaging behavior, injuries of specific body parts, various kinds of diseases, and the increased mortality rate of poultry. Welfare problems are usually multifactorial but basically, they arise when animals cannot realize their natural behavioral needs, and that is the case in most of the existing poultry rearing systems $(23,24)$. Certain species-specific behavior patterns in poultry species are very strongly motivated, such as nesting, perching, dust bathing, and scratching; if the birds are not allowed their expression that leads to frustration, abnormal behavior manifesting and/or to injury $(17,22)$. The wounds cause physical pain to the birds and may also be a source of infection and disease (22).
Abnormal behavior may cause damage to the animal itself or its conspecifics. Behaviors harmful for the animal are feather-plucking (self-removal of feathers), hysteria or "fright disease", and "excessive gregariousness" - which may lead to suffocation (1). Behaviors that harm other animals appear more frequent than previous and include injurious pecking (gentle and severe feather pecking, cloaca i.e. vent pecking, and cannibalistic pecking), toe pecking, aggressiveness, and bullying. Gentle feather pecking is a light, repeated pecks on the tail, wings, back, and neck of the other hen whilst the severe form is a hard, fast, and singular pecks on the tail, back, vent, and neck of the bird. The injury after removal a feather could trigger cannibalism i.e. continued pecking on the skin leading to serious bleeding and wounds which may cause the victim's death $(1,23,24,27,40)$. There are also some altered behaviors usually not directly harmful to the bird, such as stereotypic pacing, vacuum nesting, and vacuum dust bathing (1). This review considers data from the literature on common behavioral and health problems of chickens and their interrelation, as well as their linkage to the characteristics of rearing systems. 


\section{Rearing systems and the possibility of expressing the natural behaviors}

Poultry rearing systems may be classified as the cage and alternative systems and both groups comprise a wide variety of different models. The use of cages has the same limitations in different countries. The conventional barren cages have been banned for laying hens in the EU since 2012 by Directive 1999/74/EC but enriched i.e. furnished cages are available $(21,22,27,36)$. Cage systems for broilers are in use in some parts of the world (44). However, considering welfare aspects and consumers' demands, the development of alternative (non-cage) systems for both, broilers and laying hens is encouraged $(23,28,45)$ : floor, aviary and free-range systems. These systems for broilers have no nests and commonly have no perches. In free-range system birds may use outdoor areas i.e. verandas and areas covered with vegetation $(22,47$, 48).

Domestic fowls always tend to exhibit behavior very similar to their progenitor - the Jungle fowl (17). Alternative systems are superior regarding freedom of movement and fulfillment of behavioral needs, which is limited or completely disabled in conventional cages. The use of furnished cages allows for the expression of behaviors such as perching, nesting, and dust bathing, whilst loose housing systems additionally allow for activities such as walking, wing flapping, and foraging. On the other hand, alternative systems may have sideeffects that cause other welfare problems (22). Many problems arise directly or indirectly due to agonistic interactions in the production group which may consist of several thousand to a few tens of thousands of birds in one facility whilst chickens normally live in a small, mixedsex and -age family groups of 5 to 30 birds (24). Both in nature and farm conditions ranking begins from the moment when unfamiliar birds are put together. Method of establishing and maintaining a hierarchy is by fighting and pecking the head of other bird, what is called "a pecking order." In commercial conditions, this behavior can turn into aggressiveness and may lead to serious injuries in the area of the head and neck, including comb, wattles, and eyes (24). Increased aggression as well as and stereotyped pacing behavior may be a form of response to severe or long-term frustration and suffering in adverse conditions $(18,20)$.

Chickens also peck to escape from the eggshell, to feed, to drink, to explore, and to obtain and keep personal space. Searching for food is performed by ground pecking and scratching with their feet, and in nature, it takes the most time of the day (24). Beak trimming, a practice still performed in many countries for preventing injurious pecking, makes difficult for birds to perform the abovementioned activities but also to orient themselves in freerange rearing (26). In systems without litter, some of the elements of foraging may be directed at other birds' feathers rather than the feed (3). Injurious pecking may be a serious problem in all systems and is especially difficult to control in the large-group furnished cages and the noncage systems (22).

Dust bathing, together with preening, is a common strategy for feather and skincare (24). Birds that cannot perform either of these two behaviors (e.g. due to the lack of a dustbathing substrate or shortened beak) may have a severe problem with ectoparasites (7) such as red mite (Dermanyssus gallinae) (22). A form of preening behavior which domestic fowl may show after mild or short-term frustration is "displacement preening" (19). Displacement behavior usually occurs when an animal is torn between two conflicting drives, such as fear and aggression (4).

In the case of high air temperature thermoregulation is mainly conveyed by emitting evaporated water via respiratory organs, and a certain amount of warmth loss also occurs via the skin. When the air temperature is low, birds lift the feather and let the air go in making a layer of warm air around the body. Therefore the full feather cover is very important for cold protection, and also for protection against skin abrasions. Losing and re-growing feathers ("molting") normally occurs every year when the days get shorter. Feather loss is also possible due to stress, sudden weather changes, dehydration, overcrowding, contact with equipment, feather pecking, nutrient dysbalance, etc. (24).

Sleeping behavior is performed by roosting high off the ground. In reaching a branch or a perch chickens move in a specific way: when they go up, they jump on the branch and gradually jump to a higher one, but when they go back, they fly down directly from the branch to the ground using their wings. Damage or loss of feathers on the wings makes birds less efficient in maintaining balance (31), which can be a problem in using perches and flight control during landings. Long-term sitting on perch are common in the systems where the movements are restricted as in furnished cages. This may lead to developing deformation of the keel bone in laying hens which is very rarely observed in systems where perches are absent $(16,22,39,41)$. Deformations are also noticed in systems where birds roost on objects such as the edges of feed troughs, water pipes, wires or litter boxes, thereby applying pressure to the keel (22). In the collision with housing structures and other birds, especially during failed landings, keel bone fractures in layers may occur (29). Fractures have been noticed mainly in aviaries and other non-cage litter systems $(6,38)$. Both deformations and fractures of the keel bone (commonly named "Keel Bone Damage" or KBD) have been reported as highly frequent, multifactorial welfare problems of commercially raised laying hens $(16,29)$. 


\section{Environmental factors triggering behavioral and health problems in chickens}

The environment in a poultry house is a combination of different factors that interact. One of the main tasks in indoor housing systems is maintaining a good aerial environment (i.e. air quality), which considers that the temperature, humidity, dust level and concentrations of certain gasses should be controlled and kept within recommended limits $(11,13)$.

Air temperature and humidity are affected by stocking density, season and ventilation rate. Air humidity also depends on indoor temperature, type of drinkers, water spillage, litter type, and other factors (14). Mutual action of both parameters influences the thermal comfort of the birds (42). Elevated values of these two parameters may cause thermal stress and death.

Factors affecting airborne dust and ammonia content include litter type and quality, birds' activity, stocking density, manure handling, ventilation rate, and indoor temperature and air humidity. Dust and ammonia levels are commonly high in aviaries and floor housing systems, whereas they are usually lower in furnished cages $(9,10)$. Dust particles are usually a carrier of bacteria, fungi, bacterial toxins, and mycotoxins. In laying hens exposed to respirable dust for a longer period, a hypersensitivity reaction and respiratory diseases may occur $(9,10)$. Similarly, ammonia exposure results in the formation of lesions in the respiratory tract, higher predisposition to respiratory disease and secondary infections, as well as keratoconjunctivitis $(5,10)$. Elevated ammonia levels are correlated with an increased level of stress hormones, and potentially to the behaviors indicative of stress as well (15) such as damaging behaviors. The harmful effect can be intensified by the simultaneous occurrence of other stressors, such as heat and humidity (42).

Litter quality affects the occurrence of respiratory diseases and has a direct influence on the skin. Wet litter is a major risk factor for contact dermatitis lesions i.e. footpad dermatitis, hock burns and breast dermatitis in broiler chickens (13). The lesions are common in heavy birds that spend most of the day time sitting, e.g. due to leg weakness (49). Moisture content in the litter is associated with litter material, high stocking density, diarrhea in birds, water consumption and diet composition which affects the amount, water contents and viscosity of feces $(2,13,14,43)$.

Light management (which includes photoperiod, light intensity, source and wavelength of light) is an important tool in regulating broiler and laying hens' production and behavior. Broilers provided with sufficient dark periods have fewer health-related problems, including sudden death syndrome ("flip-over disease"), ascites syndrome associated with pulmonary hypertension, spiking mortality syndrome, eye enlargement, tibial dyschondroplasia, and other skeletal disorders $(13,34,35)$. Dimming the light is one of the effective measures in the case of problems with feather pecking during the laying period $(12,27)$.

Some systems provide lower density (i.e. organic and free-range systems) and the cage density is higher than in most floor systems. High density reduces locomotion and ground pecking, final body weight, feed intake, and feathering $(33,13,25)$. It increases the time that birds spend sitting and behavioral disturbances in the last week of broilers rearing, and there are more scratches and bruising on the body surface. The effects may be magnified or caused by increased temperature, humidity or litter moisture $(13,25)$.

Both restricted movement and disturbed rest may impact birds' physical development and the occurrence of leg deformations which predispose to further behavioral restriction (13). Restricted movement is considered as the main factor for progressive osteoporosis ("cage layer fatigue") development in hens in conventional cages during the laying period. It is manifested as skeletal weakness and bone fragility which may lead to bone fractures and sudden death. Keel bone damage also reduces birds' mobility, increase time spent in the nest, and it is linked with bumble foot and poor feather cover $(30,38)$ as well as with the consumption of more feed and water (32). Bone strength has been found better in systems where pullets and hens can exercise, including furnished cages, comparing to conventional cages. Factor related to "fatty liver hemorrhagic syndrome" is also restricted locomotion $(22,37)$, in combination with high environmental temperature and a high level of stress (22).

\section{Other diseases related to rearing system}

Diseases related to the production system are multifactorial and involve genotype, high production performances, rearing system and technology, diet composition, pathogen exposure, etc. (22). In such a way, housing systems in which stressors are present e.g. crowding, social stress and lack of general stimulation may increase the risk of infection and clinical disease of the reproductive tract. Salpingitis and peritonitis in laying hens may be caused by pecking around the cloacal region which is more common in non-cage systems and aviaries when birds were not beak trimmed than in conventional cages (22).

Taking into account infectious and parasitic diseases, in non-cage systems has been recorded the higher incidence of bacterial/protozoa infections like erysipelas, E. coli, pasteurellosis and histomoniasis, and Ascaridia compared with both, furnished and conventional cages. Systems rich in fittings such as roosts, nests, and slatted floors are more demanding in terms of implementing thorough cleaning and disinfection, and there are areas 
where parasites, mainly red mites, may live and survive. The risk of coccidiosis can be increased e.g. by cumulating the feces under perches (22). Pathogens and parasites that could be directly transmitted from other domesticated or wild (migratory) birds are more prevalent in outdoor i.e. free-range systems (47).

\section{Discussion and Conclusion}

This paper presents a brief overview of the most significant behavioral and health i.e. welfare problems in one poultry species, but some of the problems are noticed in other domestic fowls reared in similar conditions, e.g. contact dermatitis in turkey (43). Each of the existing systems and the technological solutions for laying hens or broiler chicken is associated with certain welfare problems. The ideal system has been not created yet and in all of them some of the behavioral needs are deprived; the natural behavior and the needs of animals are principally incompatible with the production goals.

The welfare problems are caused both by the system design and by its improper use. For instance, to achieve high production, contemporary systems for laying hens are based on a high stocking density, with an automated process of feeding, manure removal, microclimate control and control of the animals. Generally, it is easier to carry out all of that in a cage system, which is also more convenient in terms of controlling infectious and parasitic diseases and achieving cleanliness of eggs, and producers usually prefer it. In a desire for higher profits, sometimes they keep more birds per square meter than recommended, and in this way, they reduce already limited space. Consequently, the birds come more into collision with equipment and to each other, and thus damage and lose the feathers. The increase in the number of birds is an additional burden for the ventilation system, which is further contributed by the increased quantity of feces. If the manure removal system is not regularly in operation and/or if the collected manure is kept in the facility for days or even weeks, all parameters of the microclimate may be above the recommended values and the conditions in the facility may be very harmful to the hens but also the workers. Avian behavior is largely dependent on the housing system and microclimate (46), and providing, among other, environmentally stable temperature, lighting, and air quality conditions may safeguard against the development of feather pecking (8). Therefore, in the above-described conditions, the appearance of harmful behaviors is quite expected.

Another example is related to the maintenance of equipment. If the water is constantly dripping from some of the nipple drinkers, the litter underneath becomes wet; warm and moist bedding together with the presence of organic matter from the feces is an ideal medium for the survival of microorganisms and parasites from feces as well as harmful gases production, which increases risk of the occurrence of dermatitis and other diseases.

There are many more examples of how producers may contribute to the poultry welfare problems occurrence. Poor welfare is usually associated with a decrease in productivity $(30,32)$ and may also impact animal products' quality $(23,32)$ which posing financial concerns for producers. Wherefore, poor welfare is also opposite to production goals. In contrast to the period when the development of industrial poultry rearing systems began, nowadays, consumers can quickly obtain through the media various information on how poultry is grown and the quality of poultry products they use in nutrition. Based on the way how and which information has been presented, it may contribute to showing poultry production in a poor context and make harm the producers and the entire poultry industry. The goal is something else, to find the best solution that will strike a balance between producer goals, the right of consumers to get a quality product they can afford and the right of production animals to live according to their needs and to end their lives humanely. Regarding that, continuous work on improving existing rearing systems is as important as the work on better informing the producers and the public on poultry welfare problems.

\section{Acknowledgments}

The authors acknowledge the COST Action CA15224 for giving support in the research of keel bone damage in laying hens and strengthening collaboration between research institutions from different countries. The paper is also supported by the Ministry of Science and Technological Development, Republic of Serbia (Project TR 31033).

\section{Conflict of Interest}

The authors declared that there is no conflict of interest.

\section{References}

1. Appleby MC, Mendi JA, Barry OH (2004): Behaviour, Causes and effects. In: Poultry behaviour and welfare. CABI Publishing. The UK.

2. Avcılar ÖV, Kocakaya A, Onbaşılar EE, et al (2018): Influence of sepiolite additions to different litter materials on performance and some welfare parameters of broilers and litter characteristics. Poultry Sci, 97, 3085-3091.

3. Blokhuis H J (1986): Feather pecking in poultry: Its relation with ground pecking. Appl Anim Behav Sci, 16, 63-67.

4. Breed MD, Moore J (2012): Homeostasis and Time Budgets, 99-123. In: Animal Behavior, Elsevier.

5. Bullis KL, Snoeyenbos GH, Roekel HV (1950): $A$ keratoconjunctivitis in chickens. Poult Sci, 329, 386-389. 
6. Campbell DLM, Goodwin SL, Makagon MM, et al (2016): Failed landings after laying hen flight in a commercial aviary over two flock cycles. Poult Sci, 95:18897.

7. Chen BL, Haith KL, Mullens BA (2011): Beak condition drives abundance and grooming-mediated competitive asymmetry in a poultry ectoparasite community. Parasitology, 138, 748-757.

8. Daigle CL (2017): Chapter 11 - Controlling Feather Pecking and Cannibalism in Egg Laying Flocks. In: Patricia Hester (ed.) Egg Innovations and Strategies for Improvements. London, UK: Academic Press.

9. David B, Oppermann Moe R, Michel V, et al (2015): Air Quality in Alternative Housing Systems May Have an Impact on Laying Hen Welfare. Part I-Dust. Animals, 5, 495-511.

10. David B, Mejdell C, Michel V, et al (2015): Air Quality in Alternative Housing Systems May Have an Impact on Laying Hen Welfare. Part II-Ammonia. Animals, 5, 886896.

11. DEFRA (2002): Code of recommendations for the welfare of livestock: meat chickens and breeding chickens, Department for Environment, Food and Rural Affairs. DEFRA Publications, London.

12. de Goede D, Gremmen B, Rodenburg BT, et al (2013): Reducing damaging behaviour in robust livestock farming. NJAS-Wageningen Journal of Life Sciences, 46-53.

13. de Jong I, Berg C, Butterworth A, et al. (2012): Scientific report updating the EFSA opinions on the welfare of broilers and broiler breeders. EFSA, Supporting Publications 2012: EN-295.

14. Dinev I, Denev S, Vashin I, et al (2019): Pathomorphological investigations on the prevalence of contact dermatitis lesions in broiler chickens, J Appl Anim Res, 47, 129-134.

15. Drake KA, Donnelly CA, Stamp Dawkins M (2010): Influence of rearing and lay risk factors on propensity for feather damage in laying hens. Br Poult Sci, 51, 725-733.

16. Đukić Stojčić M, Perić L, Relić R, et al (2017): Keel bone damage in laying hens reared in different production systems in Serbia. Biotechnol Anim Husb, 33(4), 487-492.

17. Duncan IJH (1998): Behavior and Behavioral Needs. Poult Sci, 77, 1766-1772.

18. Duncan IJH, Wood-Gush DGM (1971): Frustration and aggression in the domestic fowl. Anim Behav, 19, 500-504.

19. Duncan IJH, Wood-Gush DGM (1972): Thwarting of feeding behavior in the domestic fowl. Anim Behav, 20, 444-451.

20. Duncan IJH, Wood-Gush DGM (1972a): An analysis of displacement preening in the domestic fowl. Anim Behav, 20, 68-71.

21. European Commission (EC) (1999): Council directive 1999/74/EC of 19 July 1999. Laying down minimum standards for the protection of laying hens. Official Journal of the European Communities L, 203, 53-57.

22. European Food Safety Authority (EFSA) (2005): The welfare aspects of various systems of keeping laying hens. The EFSA Journal, 197, 1-23.

23. El-Deek A, El-Sabrout K (2019): Behaviour and meat quality of chicken under different housing systems. World Poultry Sci J, 75, 105-114.
24. Ekesbo I (2011): Domestic Fowl (Gallus gallus domesticus). In: Farm Animal Behaviour: Characteristics for Assessment of Health and Welfare. CABI Publishing. The UK.

25. Estevez I (2007): Density allowances for broilers: Where to set the limits? Poult Sci, 86, 1265-1272.

26. Freire R, Eastwood MA, Joyce M (2011): Minor beak trimming in chickens leads to loss of mechanoreception and magnetoreception. J Anim Sci, 89, 1201-1206.

27. Gilani AM, Knowles TG, Nicol CJ (2013): The effect of rearing environment on feather pecking in young and adult laying hens. Appl Anim Behav Sci, 148, 54-63.

28. Gonçalves S, Ferreira R, Pereira I, et al (2017): Behavioral and physiological responses of different genetic lines of free-range broiler raised on a semi-intensive system. J Anim Behav Biometeorol, 5, 112-117.

29. Harlander-Matauschek A, Rodenburg TB, Sandilands V, et al (2015): Causes of keel bone damage and their solutions in laying hens. Worlds Poult Sci J, 71, 461-472.

30. Herkens JLT, Delezie E, Rodenburg TB, et al (2016): Risk factors associated with keel bone and foot pad disorders in laying hens housed in aviary systems. Poult Sci, 95, 482-488.

31. LeBlanc S, Tobalske B, Quinton M, et al (2016): Physical Health Problems and Environmental Challenges Influence Balancing Behaviour in Laying Hens. PLoS ONE 11(4): e0153477.

32. Nasr MAF, Murrell J, Nicol CJ (2013): The effect of keel fractures on egg production, feed and water consumption in individual laying hens. Br Poult Sci, 54, 165-170.

33. Onbaşılar EE, Poyraz Ö, Çetin S (2008): Effects of breeder age and stocking density on performance, carcass characteristics and some stres parameters of broilers, Asian Australas J Anim Sci, 21, 262 - 269.

34. Onbaşılar EE, Erol H, Cantekin Z, et al (2007): Influence of intermittent lighting on broiler performance, incidence of tibial dyschondroplasia, tonic immobility, some blood parameters and antibody production, Asian Australas $\mathbf{J}$ Anim Sci, 20, 550 - 555.

35. Onbaşılar EE, Poyraz Ö, Erdem E, et al (2008): Influence of lighting periods and stocking densities on performance, carcass characteristics and some stress parameters in broilers. Arch Geflügelk, 72, 193-200.

36. Onbaşılar EE, Ünal N, Erdem E, et al (2015): Production performance, use of nest box, and external appearance of two strains of laying hens kept in conventional and enriched cages, Poult Sci, 94, 559-564.

37. Onbaşılar EE, Erdem E, Ünal N, et al (2016): Comparison of liver and bone health of two laying hen strains kept in different cage systems. Europ Poult Sci, 80, $1-9$.

38. Riber AB, Casey-Trott TM, Herskin MS (2018): The Influence of Keel Bone Damage on Welfare of Laying Hens. Front Vet Sci, 5, 6.

39. Rodenburg TB., Tuyttens FAM, De Reu K, et al (2008): Welfare assessment of laying hens in furnished cages and non-cage systems: An on-farm comparison. Animal Welfare, 17, 363-373.

40. Rodenburg TB, Van Krimpen MM, De Jong IC, et al (2013): The prevention and control of feather pecking in 
laying hens: identifying the underlying principles. World Poultry Sci J, 69, 361-374.

41. Sandilands V, Moinard C, Sparks NHC (2009): Providing laying hens with perches: Fulfilling behavioural needs but causing injury? Br Poult Sci, 4, 395-406.

42. SCAHAW (2000): The welfare of chickens kept for meat production (broilers). Scientific Committee on Animal Health and Animal Welfare. European Commission, Health and Consumer Protection Directorate General, Brussels, Belgium.

43. Shepherd EM, Fairchild BD (2010): Footpad dermatitis in poultry. Poult Sci, 89, 2043-2051.

44. Shields S, Greger M (2013): Animal Welfare and Food Safety Aspects of Confining Broiler Chickens to Cages. Animals (Basel), 3, 386-400.

45. Şimşek ÜG, Baykalir Y, Erişir M, et al (2018): Effects of conventional and organic rearing systems and hen age on oxidative stress parameters of blood and ovarian tissues in laying hens. Ankara Univ Vet Fak Derg, 65, 85-91

46. Sosnówka - Czajka E, Herbut E, Skomorucha I (2010): Effect of different housing systems on productivity and welfare of laying hens. Ann Anim Sci, 10, 349-360.

47. Sossidou EN, Dal Bosco A, Elson HA, et al (2011): Pasture-based system for poultry production: implications and perspectives. World Poultry Sci J, 67, 47-58.

48. Sossidou EN, Dal Bosco A, Castellini C, et al (2015): Effects of pasture management on poultry welfare and meat quality in organic poultry production systems. World Poultry Sci J, 71, 375-384.

49. Stojcic MD, Bessei W (2009): The effect of locomotor activity and weight load on bone problems in fast and slow growing chickens. Arch Geflügelk, 73, 242-249.

50. Vaarst M, Steenfeldt S, Horsted K (2015): Sustainable development perspectives of poultry production. World Poultry Sci J, 71, 609-620. 